\title{
Recurrent anaemia due to ischaemic colonic ulceration caused by cholesterol embolism
}

\author{
David J. Grant, D.S.A. Sanders' ${ }^{1}$, Marion E.T. McMurdo and M.H. Lyall ${ }^{2}$ \\ Departments of Medicine, ${ }^{1}$ Pathology and ${ }^{2}$ Surgery, Ninewells Hospital and Medical School, Dundee \\ DD1 9SY, UK
}

\begin{abstract}
Summary: We describe an elderly patient with generalized atherosclerosis who presented with recurrent iron-deficiency anaemia. He underwent right hemicolectomy which revealed ischaemic colonic ulceration caused by cholesterol embolism. Surgery appeared to be curative. Cholesterol embolism should be considered as a possible cause of unexplained gastrointestinal blood loss in the elderly.
\end{abstract}

\section{Introduction}

Embolization of cholesterol crystals from ulcerated atherosclerotic plaques can give rise to a wide variety of clinical manifestations. In the gastrointestinal tract, these include frank haemorrhage, ${ }^{1}$ diarrhoea, ${ }^{2}$ abdominal pain, stricture, ${ }^{3,4}$ and pseudopolyp formation. ${ }^{5}$ We describe a patient who presented with recurrent anaemia in whom cholesterol embolism leading to ischaemic ulceration of the large bowel was the cause of chronic blood loss.

\section{Case report}

An 81 year old man presented to the Geriatric Unit in June 1990 with increasing shortness of breath. In 1985 he had presented to the Surgical Department with an iron-deficiency anaemia, haemoglobin $6.1 \mathrm{~g} / \mathrm{dl}$. Faecal occult bloods were positive. At colonoscopy, three small tubular adenomata were removed; gastroscopy was normal. Follow-up colonoscopies showed only tiny metaplastic polyps which were not removed. In 1988 he suffered a transient ischaemic attack; a carotid vasoscan showed bilateral external carotid and left internal carotid stenoses. He continued to require intermittent transfusion. Repeated gastroscopies failed to show a source of blood loss until March 1989 when a gastric ulcer was diagnosed. This had healed after 4 months treatment with ranitidine but he continued to require transfusion. In addition, he was

Correspondence: D.J. Grant, M.A., M.B., B.S., M.R.C.P., Section of Ageing and Health, Department of Medicine, Ninewells Hospital and Medical School, Dundee DD1 9SY, UK.

Accepted: 7 September 1992 admitted in September 1989 with small bowel obstruction which settled with conservative management.

The patient was a non-insulin-dependent diabetic and had been a heavy smoker. There was a history of intermittent claudication. There was no history of haematemesis or melaena, although the stools had been dark. There was a history of occasional epigastric pain which was related to exertion.

On examination he was profoundly anaemic. There was a right carotid bruit; foot pulses were absent. Abdominal examination was unremarkable. His haemoglobin was $6.4 \mathrm{~g} / \mathrm{dl}, \mathrm{MCV} 69 \mathrm{fl}$, with a hypochromic microcytic film. He was transfused six units of blood (he had by then received 36 units in total). Faecal occult bloods remained positive. Unremarkable gastroscopy, barium enema and colonoscopy had been performed within the last 6 months, so a superior mesenteric angiogram was performed. This was suggestive of an angiodysplastic lesion in the caecum and he was referred for right hemicolectomy. He made an uneventful recovery from surgery and remained well and independent requiring no further transfusion until he died of a myocardial infarction 9 months later. Permission for a post-mortem examination was refused.

The right hemicolectomy specimen was received fresh allowing specimen angiography to be carried out. No evidence of angiodysplasia was seen on this $\mathrm{X}$-ray, nor was there an obvious arterial stenosis. On opening the bowel multiple small shallow mucosal ulcers were noted in the caecum and ascending colon. Histology showed focal ulceration of the superficial portion of the colonic mucosa 
covered by a fibrinous exudate, in keeping with acute ischaemic colitis (Figure 1). Small submucosal vessels adjacent to and distant from areas of ulceration showed occlusion of the lumen by cholesterol clefts surrounded by a foreign body type granulomatous reaction and with an eosinophil polymorph infiltration (Figure 2). No ectatic vessels were seen in the multiple sections examined to suggest angiodysplasia.

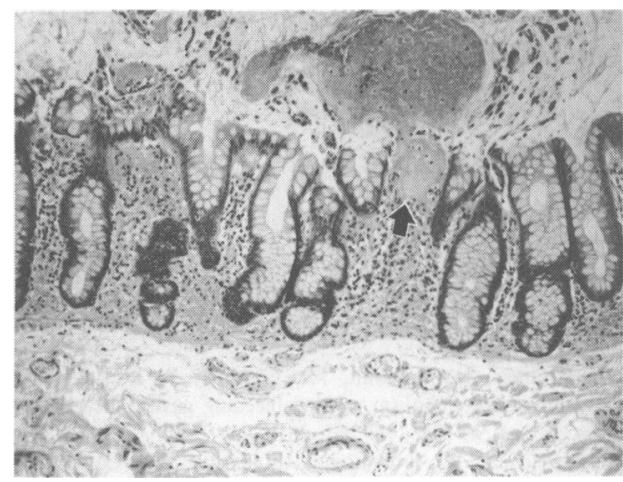

Figure 1 Colonic mucosa with a focus of superficial ischaemic ulceration (arrowed) covered by a fibrinous exudate (H\&E, $\times 360)$.

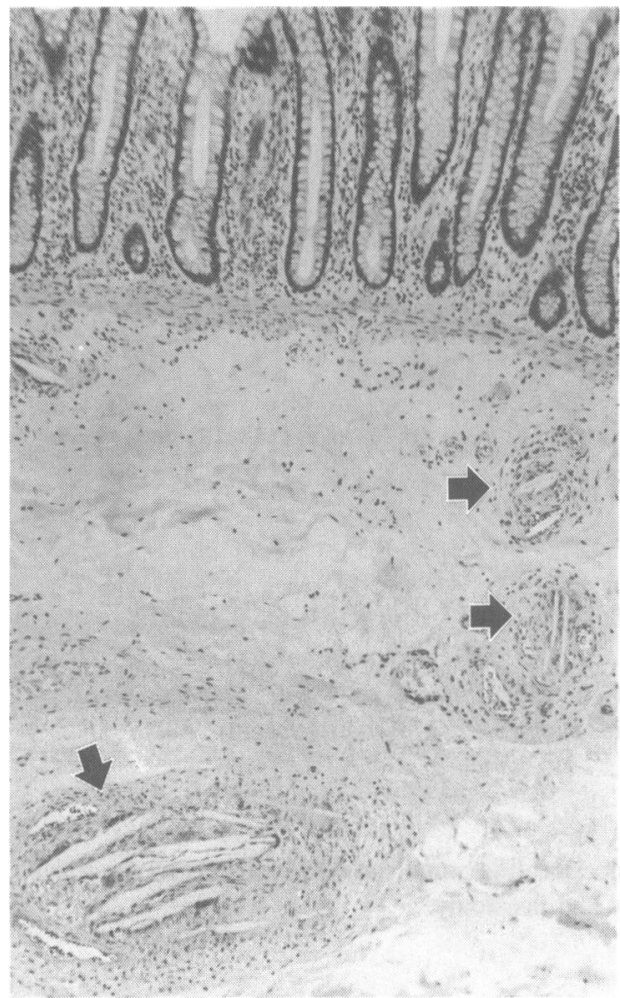

Figure 2 Colonic submucosal vessels occluded by cholesterol clefts surrounded by a foreign body granulomatous reaction (arrowed) (H\&E, $\times 80)$.

\section{Discussion}

Cholesterol crystal embolization can be difficult to diagnose in life. Patients may present with a systemic illness resembling polyarteritis nodosa with skin lesions and splinter haemorrhages; lower limb ischaemia, renal failure, acute pancreatitis and spinal cord infarction may occur. ${ }^{6}$ The disease most commonly affects elderly males with a history of hypertension and evidence of generalized atherosclerosis. It frequently follows an invasive procedure such as aortic surgery, angioplasty, angiography or cardiac catheterization ${ }^{7}$ and may occur after thrombolytic therapy. ${ }^{8}$ Spontaneous cholesterol embolism is less common; a recent British postmortem series suggested an incidence of $1.9 \%{ }^{6}$

A variety of presentations of cholesterol embolism in the gastrointestinal tract have been described; in a large historical series, frank upper or lower gastrointestinal haemorrhage was the most common, being present in 21 out of 221 total case reports. ${ }^{1}$ Subsequently, Farouhar et al. ${ }^{9}$ described two patients with bleeding gastric ulcers which were treated surgically and found to be secondary to small arteriolar occlusion from cholesterol embolism. One patient with haematemesis is reported in whom endoscopy revealed multiple duodenal polypoid lesions which resolved spontaneously; biopsy showed cholesterol clefts and granuloma formation. ${ }^{5}$ In the large bowel, Moolenaar et al. ${ }^{10}$ described a patient in whom cholesterol emboli caused ischaemic perforation of the sigmoid colon (and later of the gallbladder as well) and O'Briain et al. ${ }^{11}$ described three patients with frank rectal bleeding in whom biopsy revealed cholesterol atheroemboli in rectal ischaemic ulcers and in colorectal adenomatous polyps; the disease resolved on conservative management. Other manifestations recently described include painless diarrhoea due to jejunal disease, ${ }^{2}$ small bowel stricture formation, ${ }^{3,4}$ and an ischaemic caecal infarct mimicking carcinoma on barium enema and colonoscopy. ${ }^{12}$ All these patients described had evidence of generalized atherosclerosis.

The exact mechanism by which cholesterol crystals are released into the mesenteric circulation is not completely understood. They are thought to originate from the damaged surface of an atheromatous plaque in the aorta when local thrombotic repair mechanisms fail. Once released, their small size and fatty composition results in their lodging in small deep submucosal arterioles. Whilst this may be inconsequential, the resulting mucosal ischaemia may lead to mucosal swelling, congestion, ulceration and necrosis. The diagnosis can be difficult to make endoscopically because timing is critical. If colonoscopy is delayed, a shallow ulcer may have re-epithelialized, and even if performed before healing, biopsy must include the submucosa for cholesterol clefts to be visualized. ${ }^{11}$ 
To our knowledge this is the first report of recurrent anaemia without frank gastrointestinal haemorrhage as a presentation of cholesterol embolism. This elderly male patient, athough not hypertensive, had many risk factors for this disease: he was a diabetic, an ex-smoker and had evidence of generalized atherosclerosis. We cannot be certain in retrospect for how long cholesterol embolism in the superior mesenteric axis was the source of blood loss, but right hemicolectomy appeared to be curative in this case and no other cause for bleeding was found on close examination of the specimen. The interval of one month between

\section{References}

1. Fine, M.J., Kapoor, W. \& Falanga, V. Cholesterol crystal embolization: a review of 221 cases in the English literature. Angiology 1987, 38: 769-784.

2. Socinski, M.A., Frankel, J., Morrow, P.L. \& Krawitt, L. Painless diarrhoea secondary to intestinal ischaemia. Diagnosis of atheromatous emboli by jejunal biopsy. Dig Dis $\mathrm{Sci}$ 1984, 29: 674-677.

3. Mulliken, J.B. \& Bartlett, M.K. Small bowel obstruction secondary to atheromatous embolism: a case report and review of the literature. Ann Surg 1971, 174: 145-150.

4. Blundell, J.W. Small bowel stricture secondary to multiple cholesterol emboli. Histopathology 1988, 13: 459-462.

5. Francis, J. \& Kapoor, W.N. Intestinal pseudopolyps and gastrointestinal haemorrhage due to cholesterol crystal embolization. Am J Med 1988, 85: 269-271.

6. Cross, S.S. How common is cholesterol embolism? J Clin Pathol 1991, 44: 859-861.

7. Dahlberg, P.J., Frecentese, D.F. \& Cogbill, T.H. Cholesterol embolism: experience with 22 histologically proven cases. Surgery 1989, 105: 737-746. angiography and surgery makes it unlikely that the ischaemic changes observed were due to cholesterol embolism at aortic instrumentation. It is possible that the episode of small bowel obstruction was also a sequel of cholesterol embolism, since the healing process following an episode of extensive mucosal ischaemia can result in concentric fibrosis and narrowing of the bowel lumen. ${ }^{3}$

This case illustrates that cholesterol embolism should be considered as a possible cause of unexplained gastrointestinal blood loss in an elderly patient with atherosclerosis.

8. Queen, M., Biem, H.J., Moe, G.W. \& Sugar, L. Development of cholesterol embolization after intravenous streptokinase for acute myocardial infarction. Am J Cardiol 1990, 65: 1042-1043.

9. Farouhar, F.A., Mohit, M., Gardner, P. \& Smith, N. Cholesterol embolism causing bleeding gastric ulcers. Ann Clin Lab Sci 1988, 18: 260-265.

10. Moolenaar, W., Kreuning, J., Eulderink, F. \& Lamers, C. Ischaemic colitis and acalculous necrotising cholecystitis as rare manifestations of cholesterol emboli in the same patient. Am J Gastroenterol 1989, 84: 1421-1422.

11. O'Briain, D.S., Jeffers, M., Kay, E.W. \& Hourihane, D. O'B. Bleeding due to colorectal atheroembolism: diagnosis by biopsy of adenomatous polyps or of ischaemic ulcer. $A m J$ Surg Pathol 1991, 15: 1078-1082.

12. Chan, T., Levine, M.S. \& Park, Y. Cholesterol embolization as a cause of caecal infarct mimicking carcinoma. Am $J$ Radiol 1988, 150: 1315-1316.

\title{
Toxic megacolon with late perforation in Campylobacter colitis - a cautionary tale
}

\author{
Samir K. Vyas, Nicholas N. Law ${ }^{1}$, Simon Hill ${ }^{2}$ and Christian A. Loehry ${ }^{3}$ \\ Department of Clinical Medicine, Royal Bournemouth General Hospital, East Dorset, ${ }^{1}$ Department of \\ Microbiology, Poole General Hospital, West Dorset, and ${ }^{2}$ Department of General Surgery, Royal \\ Bournemouth General Hospital, East Dorset, UK
}

Summary: We report a case of Campylobacter-induced colitis complicated by toxic megacolon which led to colonic perforation requiring a total colectomy and ileostomy. 